\title{
Characterization Of Phases and Structures In Composites By TEM and SEM
}

\author{
Agustín Ávalos ${ }^{1}$, Eugenia Zelaya ${ }^{2}$ and Marcelo R. Esquivel ${ }^{2,3^{*}}$ \\ ${ }^{1 .}$ Instituto Sábato (UNSam - CNEA), San Martín, Buenos Aires Argentina. \\ 2. CNEA, CONICET, Centro Atómico Bariloche, Bariloche, Rio Negro Argentina. \\ ${ }^{3 .}$ UNCo-Bariloche, Bariloche, Río Negro Argentina \\ *Corresponding author: esquivel@cab.cnea.gov.ar.
}

The composites based on cerium dioxide $\left(\mathrm{CeO}_{2}\right)$ and nickel are widely demanded in different research fields including energy and environmental applications [1,2]. These required composites need to fulfill at least two common requirements. One is to use the nickel as a catalyst in the composite and the other is to use the cerium based dioxide as both a support and a conductive structure. Both requirements are somehow complex because a strong structure should also be compatible with a porous 3-D distribution of Ni. A large number of synthesis methods developed to obtain these composites are found in the bibliography. The variety of methods includes mechanical alloying in different atmospheres, sol-gel synthesis from the nitrate precursor, sequential impregnation and solution combustion synthesis. But this variety of methods is developed according to the application selected. In this work, a method of additive manufacture is done to obtain a $\mathrm{Ce}_{0.52} \mathrm{La}_{0.25} \mathrm{Nd}_{0.17} \mathrm{Pr}_{0.06} \mathrm{O}_{2}-\mathrm{Ni}$ mixture. The manufacture method is designed to obtain a porous stable structure with properly distributed Ni. In a first step, a 3-D mold is fabricated with poly-lactic acid (PLA). The method used is molten deposition modeling using a 3-D printer. The mold is filled with a Ce-based alloy $\left(\mathrm{Ce}_{0.52} \mathrm{La}_{0.25} \mathrm{Nd}_{0.17} \mathrm{Pr}_{0.06}\right)-3 \mathrm{Ni}$ mixture previously milled in a high energy mill (Retsch M100 mill). Then, the alloy-metal mixture is pressed at low pressure in a die within the mold. The sample is withdrawn and thermally treated in air and hydrogen. The final sample is shaped according to the mold. The sample nanostructure is analyzed by Transmission Electron Microscopy (TEM - FEI Tecnai G20 operated at $200 \mathrm{kV}$ ) and associated techniques. The TEM technique is used to study the composite at nano-scale to determine the individual features of each component.. The morphology, habit and forms of structures at micro-scale are studied by Scanning Electron Microscopy (SEM - FEI Inspect S50 operated at $30 \mathrm{kV}$ ). These features are observed in Figures 1 and 2. The Figure 1 shows TEM micrographs of a $\mathrm{Ce}_{0.52} \mathrm{La}_{0.25} \mathrm{Nd}_{0.17} \operatorname{Pr}_{0.06} \mathrm{O}_{2}$ particle of the $\mathrm{Ce}_{0.52} \mathrm{La}_{0.25} \mathrm{Nd}_{0.17} \mathrm{Pr}_{0.06} \mathrm{O}_{2}$-Ni mixture. Figure 1.a shows the bright field. Note the straight cuts that indicate a structure evolving in equilibrium after temperature treatment. Figure 1.b shows the dark field. Notice the two different sizes on the crystalline domains. The Figure $2 \mathrm{~b}$ shows SEM micrographs of the $\mathrm{Ce}_{0.52} \mathrm{La}_{0.25} \mathrm{Nd}_{0.17} \mathrm{Pr}_{0.06} \mathrm{O}_{2}$-Ni composite. The Figure 2.a shows the micrograph in the emissive mode. The selected particle presents a porous structure of the mixture. The Figure 2.b shows the same micrograph on the reflective mode. The atomic contrast is evidenced. The white color is assigned to $\mathrm{Ce}_{0.52} \mathrm{La}_{0.25} \mathrm{Nd}_{0.17} \mathrm{Pr}_{0.06}$ in the oxide and the grey color to $\mathrm{Ni}$. The particle boundaries are well defined in the $\mathrm{Ce}_{0.52} \mathrm{La}_{0.25} \mathrm{Nd}_{0.17} \mathrm{Pr}_{0.06} \mathrm{O}_{2}$-based component. The micrograph also shows the $\mathrm{Ni}$ distribution within the $\mathrm{Ce}_{0.52} \mathrm{La}_{0.25} \mathrm{Nd}_{0.17} \mathrm{Pr}_{0.06} \mathrm{O}_{2}$ matrix. These images indicate that the synthesis method combining additive manufacture, mechanical milling and thermal treatment lead to the formation of the desired structure. The samples obtained in this work are used to capture oxygen to purify argon /nitrogen gases.

\section{References:}

[1] M. Li, A. Van Veen. App. Catal. B: Environm. 237 (2018) p. 641.

[2] S. Kasturibai, G.P. Kalaignan. Mat. Chem. Phys. 147 (2014) p. 1042. 


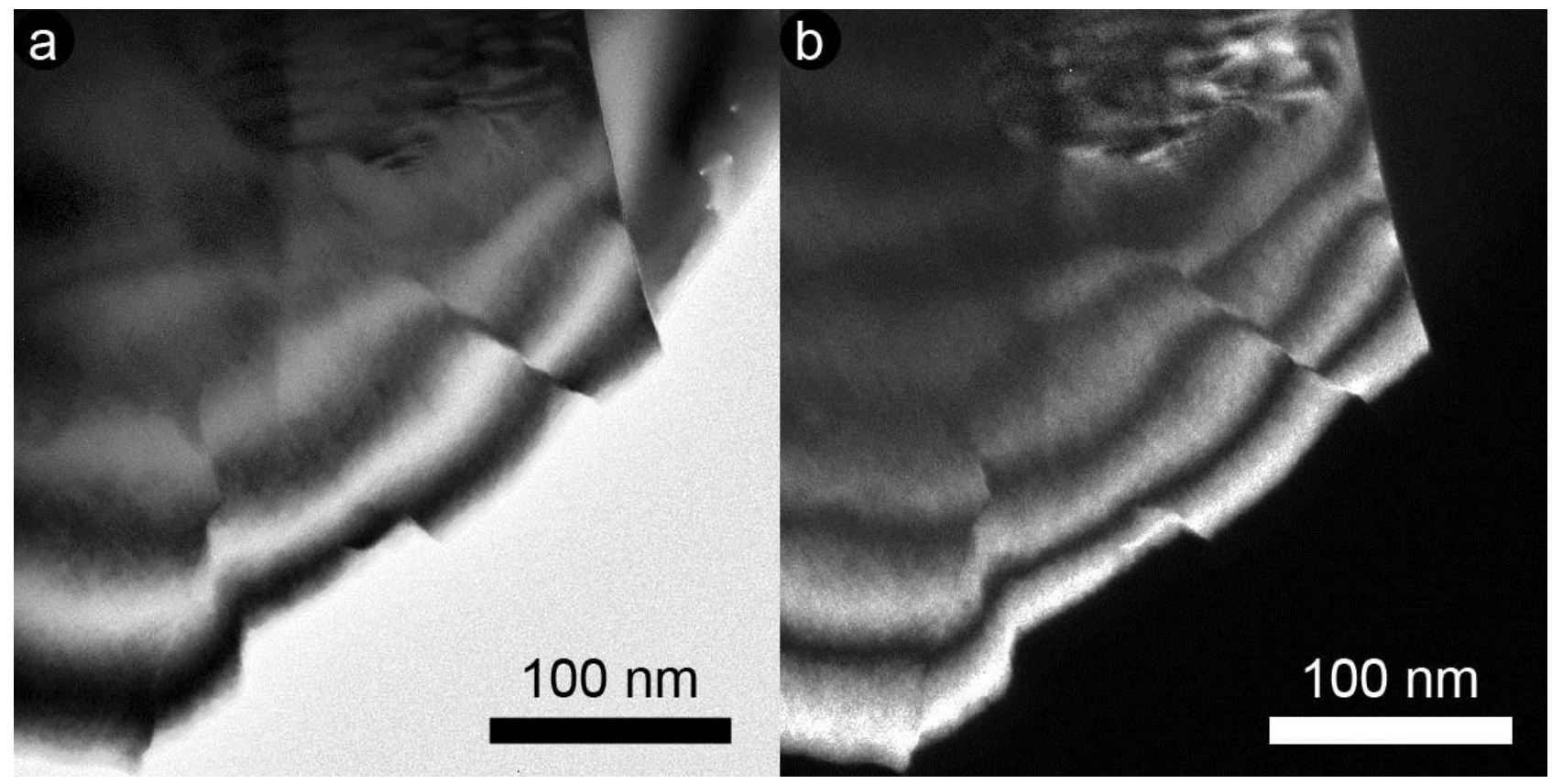

Figure 1. TEM micrographs of a $\mathrm{Ce}_{0.52} \mathrm{La}_{0.25} \mathrm{Nd}_{0.17} \mathrm{Pr}_{0.06} \mathrm{O}_{2}$ particle allocated in the $\mathrm{Ni}$ $\mathrm{Ce}_{0.52} \mathrm{La}_{0.25} \mathrm{Nd}_{0.17} \operatorname{Pr}_{0.06} \mathrm{O}_{2}$ mixture. a. Bright field. b. Dark field.

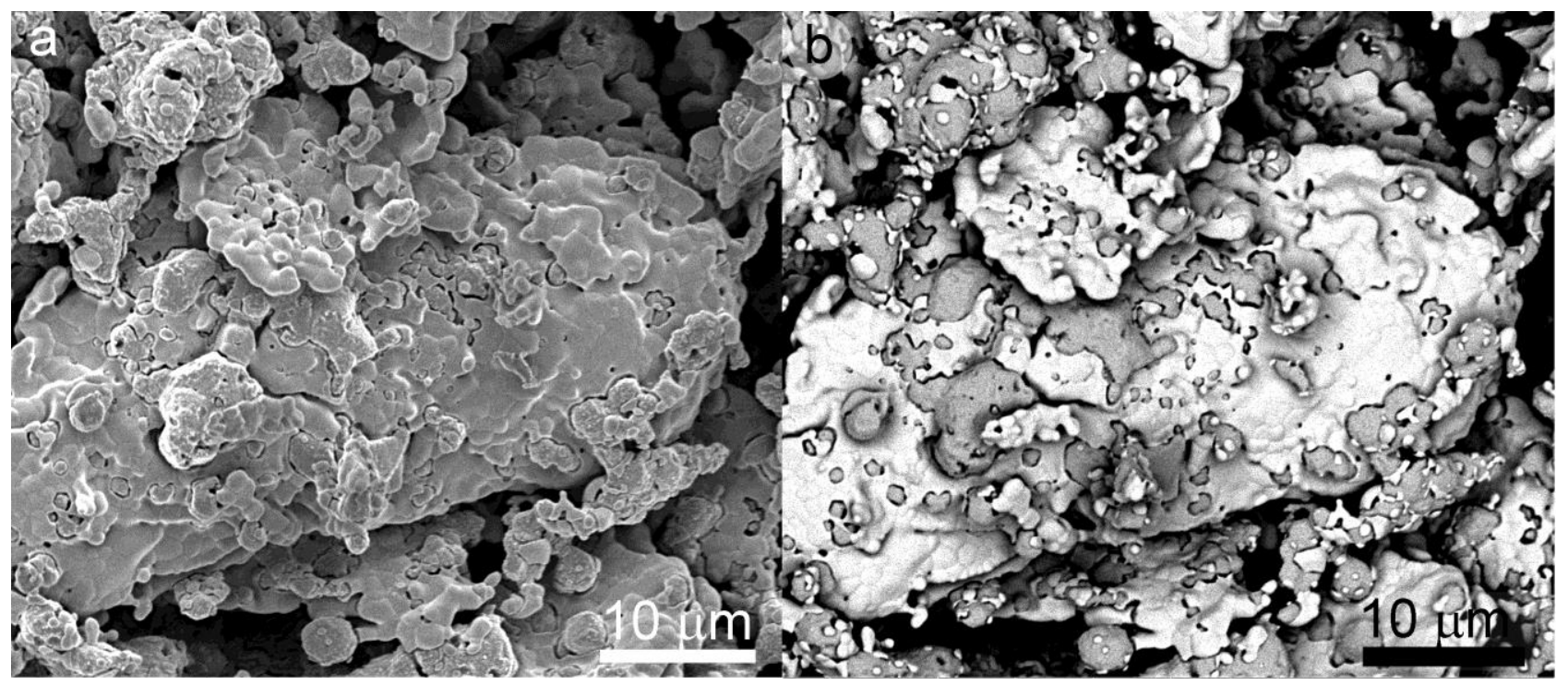

Figure 2. SEM micrographs of the $\mathrm{Ce}_{0.52} \mathrm{La}_{0.25} \mathrm{Nd}_{0.17} \mathrm{Pr}_{0.06} \mathrm{O}_{2}-\mathrm{Ni}$ composite. a. Emissive mode. b. Reflective mode showing atomic contrast. The white color is assigned to $\mathrm{Ce}_{0.52} \mathrm{La}_{0.25} \mathrm{Nd}_{0.17} \operatorname{Pr}_{0.06} \mathrm{O}_{2}$. The grey color is assigned to $\mathrm{Ni}$. 